Revista Nacional de

\title{
Logística reversa no pós-consumo de filtros do óleo lubrificante
}

Reversal logistics on the post-consumer of filters of lubrificating oil

Logística reversa en el post-consumo de filtros del aceite lubricante

\author{
Leonildo Vioto Junior \\ Pós-graduando, UNOESTE, Brasil. \\ leonildoviotojr@hotmail.com \\ Lechan Colares-Santos \\ Professor Mestre, UNOESTE, Brasil. \\ lechan@unoeste.br \\ Álvaro Costa Jardim Neto \\ Professor Mestre, UNOESTE, Brasil. \\ alvaro@unoeste.br.
}




\section{RESUMO}

O presente trabalho foi desenvolvido para analisar a cadeia reversa de pós-consumo de filtros de óleo lubrificante com foco no consumidor final, especificamente nas empresas do setor de transporte rodoviário. 0 principal objetivo deste estudo foi fazer um levantamento sobre logística reversa aplicada à destinação correta dos filtros usados e contaminados e as normas que regulamentam esse descarte adequado. Além da pesquisa bibliográfica foi aplicado um questionário a uma empresa do setor de transporte para que pudesse ser verificado empiricamente como a mesma tem trabalhado para atender as exigências da LEI 12.305/10 e minimizar os impactos ambientais causados pelo consumo de filtros lubrificantes. Os resultados demonstram que a empresa objeto do presente estudo adota práticas que coadunam as normas vigentes e contribuem com minimização do passivo ambiental gerados pelas empresas de transporte.

PALAVRAS-CHAVE: Logística reversa, Óleos Lubrificantes, Impacto ambiental.

\section{ABSTRACT}

The present work was developed to analyze the reverse chain of post-consumer of filters of lubricating oil with focus on the final consumer, specifically in the companies of the road transport sector. The main objective of this study was to make a survey on reverse logistics applied to the correct destination of used and contaminated filters and the norms that regulate this adequate disposal. In addition to the bibliographic research, a questionnaire was applied to a company of transportation sector, so that it could be verified empirically verified as the same has been working to meet the requirements of Law 12,305 / 10 and to minimize the environmental impacts caused by the consumption of filters of lubricating oil. The results demonstrate that the company researched adopts practices that are in line with the current regulations and contribute with minimization of the environmental liabilities generated by the transport companies.

\section{RESUMEN}

El presente trabajo fue desarrollado para analizar la cadena inversa de post-consumo de filtros de aceite lubricante con foco en el consumidor final, específicamente en las empresas del sector de transporte por carretera. El principal objetivo de este estudio fue hacer un levantamiento sobre logística reversa aplicada al destino correcto de los filtros usados y contaminados y las normas que regulan ese descarte adecuado. Además de la investigación bibliográfica fue aplicado un cuestionario a una empresa del sector de transporte para que pudiera ser verificado empíricamente como la misma ha trabajado para atender las exigencias de la LEI 12.305 / 10 y minimizar los impactos ambientales causados por el consumo de filtros lubricantes. Los resultados demuestran que la empresa objeto del presente estudio adopta prácticas que concaten las normas vigentes y contribuyen con minimización del pasivo ambiental generado por las empresas de transporte.

PALABRAS CLAVE: Logística inversa, Aceites Lubricantes, Impacto ambiental. 


\section{INTRODUÇÃO}

Com o advento da globalização o mercado passou a sofrer alterações constantes, as empresas passaram a competir em nível mundial e, para se manterem competitivas, tornou-se essencial possuir e manter processos bem definidos e organizados que acompanhem as evoluções desse mercado. Para superar os desafios operacionais (produzir mais em menos tempo, entregar mais rápido) entra em cena a logística.

O aumento da população, diante de um mercado cada vez mais competitivo, subsidiado por inovações tecnológicas, proporcionou o aumento do consumo e os produtos passaram a ter um ciclo de vida muito menor. Consequentemente aumentou a quantidade de resíduos gerados, impactando diretamente no meio ambiente, contribuindo para sua degradação e para a escassez de recursos naturais. $O$ crescimento desses problemas passou a preocupar a sociedade, que por sua vez passou a cobrar posicionamento do governo e das empresas quanto à questão ambiental. Novas leis foram criadas, mas, ainda assim, os problemas ambientais continuam existindo.

Uma empresa relaciona-se com o meio ambiente causando impactos de diferentes intensidades, muitas vezes com consequências irreversíveis. Empresas ambientalmente responsáveis devem agir visando a manutenção e melhoria das condições ambientais, diminuindo ações próprias agressivas ao meio ambiente e difundindo em outras empresas as práticas e conhecimentos adquiridos nesse sentido (CAVALCANTI, 2003). E justamente com o objetivo de reduzir o impacto ambiental causado pelos resíduos pós-consumo, surgiu a logística reversa.

Segundo Guarnieri (2011), enquanto a logística direta trata do fluxo no qual os produtos saem dos fornecedores e são direcionados até os clientes, a logística reversa trata o fluxo de pósvenda e pós-consumo, partindo dos clientes até a recepção e destinação pelas empresas de onde se originaram. Este artigo tem como objetivo, por meio do levantamento bibliográfico e da análise dos conceitos em trabalhos já publicados sobre logística, Política Nacional de Resíduos Sólidos e sobre logística reversa aplicada em empresas de transporte, especificamente no que diz respeito ao descarte de filtros de óleo lubrificante, apresentar quais são os principais procedimentos e normas que devem ser adotados por essas organizações para o tratamento e descarte adequado dos filtros e avaliar se as mesmas estão realmente atendendo à legislação vigente.

\section{METODOLOGIA}

Para o desenvolvimento deste trabalho o método de pesquisa utilizado foi a abordagem qualitativa que, segundo Neves (1996), compreende um conjunto de diferentes técnicas interpretativas (como entrevistas e documentos) que visam obter dados descritivos que expressam os sentidos dos fenômenos estudados. 
Quanto aos objetivos foi utilizado o método descritivo, pretendendo retratar as principais características do tema abordado, e no que se refere aos procedimentos foram utilizadas como ferramentas a pesquisa bibliográfica, a partir da consulta a livros, artigos, trabalhos acadêmicos e conceitos já publicados sobre logística reversa, e o estudo de caso. Nesse último, a principal técnica utilizada para a coleta de dados e fonte de informação foi a entrevista por meio de um questionário pré-definido, com perguntas abertas, aplicado a uma empresa do ramo de transportes, para que pudesse ser verificado empiricamente se a organização tem adotado os procedimentos de logística reversa, bem como se essa adoção é motivada por fatores legais ou consciência ambiental.

\section{REFERÊNCIAL TEÓRICO}

\section{Definição de logística}

A logística originou-se nos processos e táticas militares usadas em campo de batalha, onde era necessário montar complexos esquemas para deslocar tropas, transportar e armazenar suprimentos e armas. De acordo com a Endeavor (2015), com o final da Segunda Guerra Mundial as empresas, diante da acirrada competição no mercado, começaram a se perguntar o que poderiam aprender com essas táticas de batalha. Surgindo aí a logística empresarial. Em resumo, a logística compreende todos os processos, desde a aquisição da matéria prima, transporte, armazenamento, produção, armazenagem do produto acabado, até a entrega ao cliente, buscando reduzir o custo e tempo. Esse processo recebe o nome de Cadeia de suprimentos (Supply Chain), Ballou (2004).

Magalhães et al (2013), aponta o Conselho de Gestão da cadeia de Suprimentos norte americano (Council of Supply Chain Magnament Professionals - CSCMP) como sendo a maior referência em cadeia de suprimentos no mundo, o qual define logística da seguinte forma:

\footnotetext{
A administração logística é a parte da administração da cadeia de suprimento que planeja, implementa e controla, de forma eficiente e eficaz, o fluxo direto e reverso e a armazenagem de bens, serviços e informações relacionadas, entre o ponto de origem e o ponto de consumo, com o objetivo de atender aos requisitos do cliente.
}

Como apontado pelo CSCMP a logística possui dois fluxos, direto e reverso, que segundo Guarnieri (2011 p. 29-32), enquanto a logística direta trata do fluxo no qual os produtos saem dos fornecedores e são direcionados até os clientes, a logística reversa trata o fluxo de pósvenda e pós-consumo, partindo dos clientes até a recepção e destinação pelas empresas de onde se originaram.

A logística reversa é justamente a estratégia que cumpre o papel de operacionalizar o retorno dos resíduos de pós-venda e pós-consumo ao ambiente de negócios e/ou produtivo, considerando que somente dispor resíduos em aterros sanitários, controlados ou lixões não basta no atual contexto empresarial. 


\section{Revista Nacional de}

De acordo com Leite (2003) apud Shibao, Moori e Santos (2010), a logística reversa é a área da logística empresarial que visa equacionar os aspectos logísticos do retorno dos bens ao ciclo produtivo ou de negócios por intermédio da multiplicidade de canais de distribuição reversos de pós-venda e de pós-consumo, agregando-lhes valor econômico, ecológico e legal.

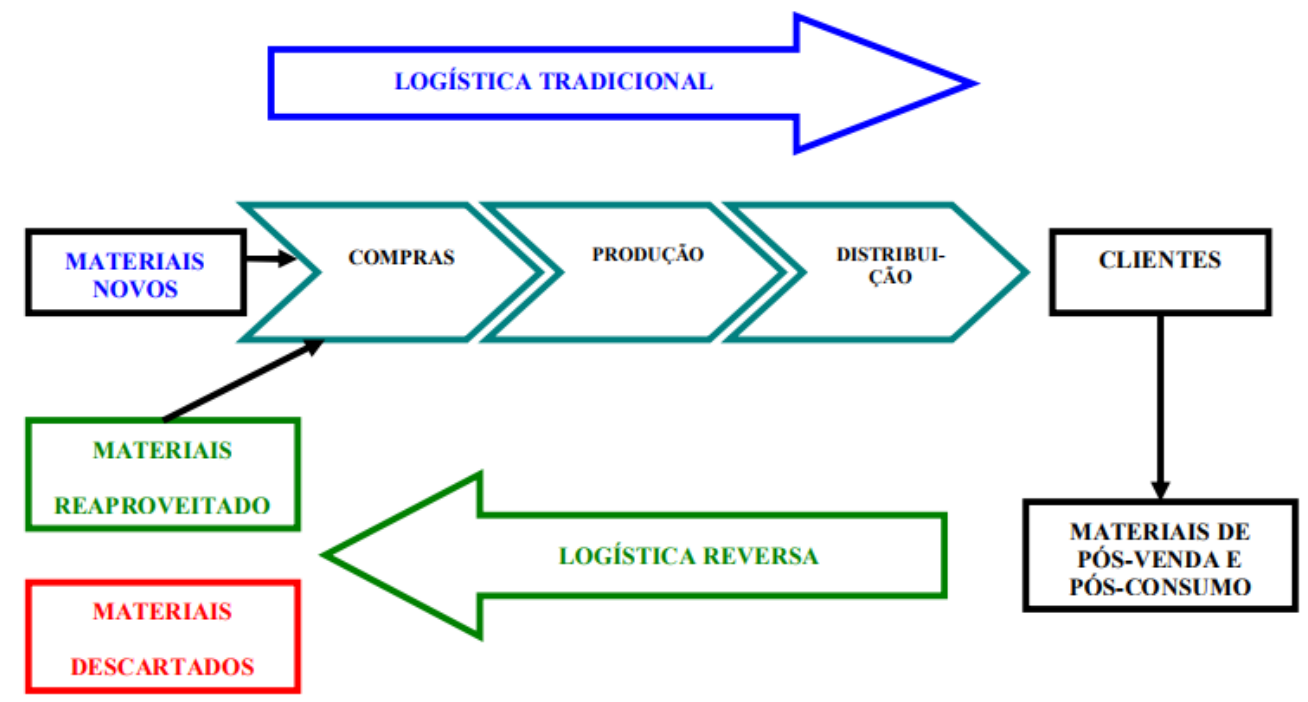

Fonte: Shibao, Moori e Santos (2010)

Como é possível observar, a logística reversa além de responsável por inserir os resíduos reaproveitáveis em um novo processo produtivo, é também responsável pelo descarte adequado dos resíduos não reaproveitáveis.

\section{Política Nacional de Resíduos Sólidos (PNRS)}

No Brasil, em agosto de 2010, foi instituída por meio da Lei $12.305 / 10$ a Política Nacional de Resíduos Sólidos (PNRS), que definiu os princípios, objetivos, instrumentos, e as diretrizes, relativas à gestão e ao gerenciamento de resíduos sólidos, incluídos os perigosos, discorrendo sobre responsabilidades dos geradores e do poder público e aos instrumentos econômicos aplicáveis em âmbito nacional.

A Lei 12.305/10 define logística reversa como:

[...] instrumento de desenvolvimento econômico e social caracterizado por um conjunto de ações, procedimentos e meios destinados a viabilizar a coleta e a restituição dos resíduos sólidos ao setor empresarial, para reaproveitamento, em seu ciclo ou em outros ciclos produtivos, ou outra destinação final ambientalmente adequada.

Em seu artigo 30 a lei atribui de forma compartilhada por toda a cadeia produtiva, a responsabilidade pelo ciclo de vida dos produtos. 


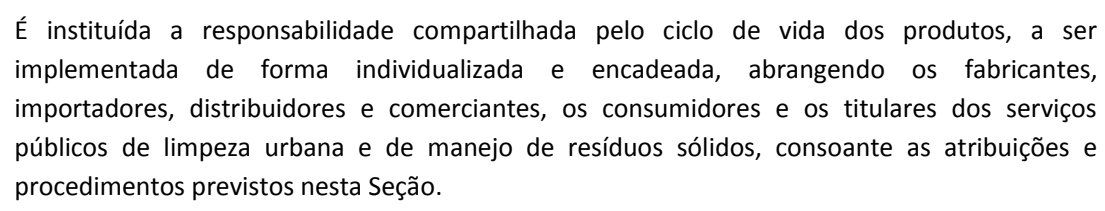

Fabricantes, importadores, distribuidores e comerciantes de determinados produtos tornaram-se obrigados a estruturar e implantar sistemas de logística reversa, independentes dos serviços de limpeza urbana. Os produtos especificados no artigo 33 são:

- Embalagens de agrotóxicos;

- Pilhas e baterias;

- Pneus;

- Lâmpadas fluorescentes de vapor de sódio e mercúrio e de luz mista;

- Óleos lubrificantes, seus resíduos e embalagens; e

- Produtos eletroeletrônicos e seus componentes.

\section{Logística reversa aplicada à cadeia de filtros de óleos lubrificantes}

O filtro de óleo é uma peça fundamental nos motores a combustão interna, pois para o funcionamento correto desses motores é essencial a lubrificação constante de suas peças móveis através de óleos que disponham do nível necessário de limpeza, de modo a evitar qualquer desgaste prematuro. É o filtro de óleo que permite a purificação contínua do óleo, retendo partículas abrasivas resultantes do desgaste normal, bem como resíduos de sujeira e combustão, sendo este substituído por completo após a respectiva vida útil.

Em 2006, com o objetivo de promover a integração entre os fabricantes de filtros automotivos, industriais, filtros destinados em aplicações em estações de tratamento de água e efluentes e fornecedores, além de realizar ações em prol do desenvolvimento e em defesa do setor, foi criada a Abrafiltros (Associação Brasileira das Empresas de Filtros e seus Sistemas Automotivos e Industriais), que reúne os principais fabricantes de filtros automotivos e industriais do País. Em julho de 2012, em cumprimento à legislação, a associação deu início a um programa pioneiro, o Descarte Consciente Abrafiltros, que coleta e recicla os filtros de óleo lubrificante automotivo de forma proporcional à quantidade comercializada pelas empresas participantes, de acordo com as metas gradativas estabelecidas nos Termos de Compromisso firmados com as Secretarias Estaduais de Meio Ambiente. Atuando inicialmente no estado de São Paulo e posteriormente Paraná e Espírito Santo, até outubro de 2017 o programa alcançou a marca de 9.208.747 filtros, recolhidos e reciclados.

O artigo que regulamenta a Lei Estadual da Política de Resíduos Sólidos do Estado de São Paulo determina que os fabricantes, distribuidores ou importadores de produtos que, por suas características, representem significativo impacto ambiental devem, mesmo após a utilização e 


\section{Revista Nacional de}

descarte desses produtos pelo consumidor final, responsabilizar-se pela coleta, tratamento e destinação final ambientalmente adequada (ALBERTINI, 2010).

Teoricamente, portanto, as empresas devem adotar as medidas necessárias para evitar que o filtro de óleo lubrificante usado venha a se misturar com produtos químicos, água e outras substâncias que possam inviabilizar a reciclagem do mesmo, respeitando a legislação relativa ao transporte de produtos perigosos.

\section{Sistema de Coleta e Reciclagem}

Segundo a Abrafiltros, a coleta e a reciclagem de filtros do óleo lubrificante necessitam de logística específica aos resíduos perigosos. O processo deve ser realizado por empresas especializadas seguindo as normas aplicáveis ao manuseio e transporte de resíduos perigosos, e a coleta deve ser feita diretamente em postos de combustível e oficinas.

De acordo com a ABNT (2004), em sua norma técnica NBR-10004, que trata da classificação de Resíduos Sólidos, o óleo lubrificante usado é classificado como Resíduo Perigoso (Classe I), por sua alta toxicidade, e o processo de reciclagem e processamento desse material deve ser feito da seguinte forma:

- O metal é encaminhado para siderúrgicas;

- O óleo contaminado para refino; e

- Os demais componentes para coprocessamento em cimenteiras (geração energética).

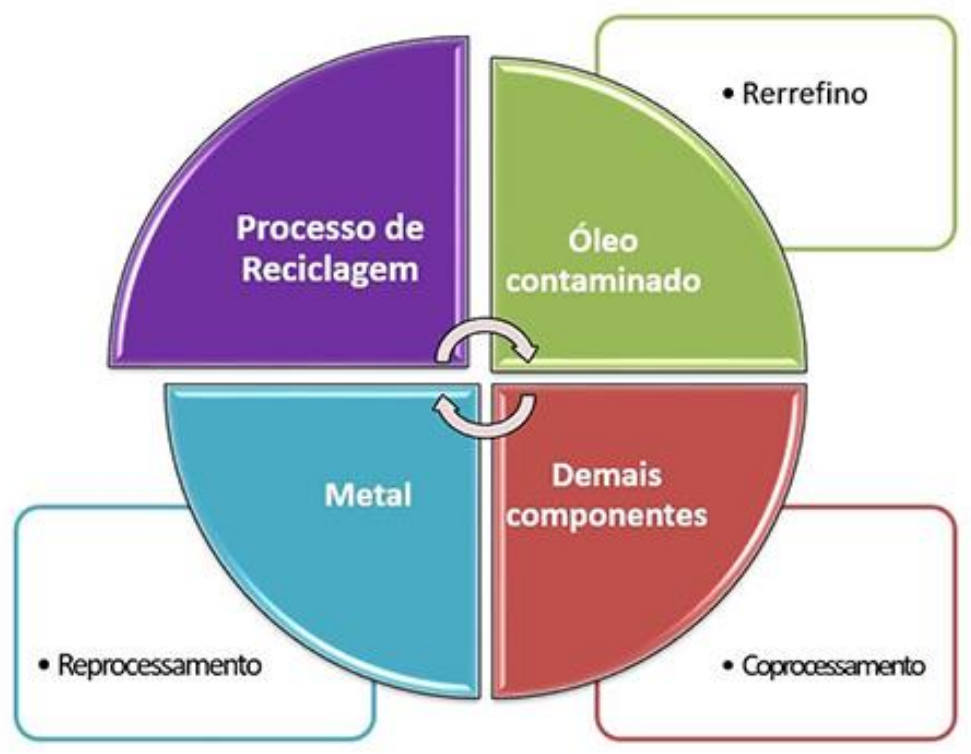

Fonte: Abrafiltros (2017)

\section{ANÁLISE DOS RESULTADOS}


A empresa que contribuiu para a verificação desse estudo está há 70 anos no mercado de transporte rodoviário de passageiros, com uma frota de mais de 300 ônibus e possui oficina própria, composta por mecânica, elétrica, tapeçaria, borracharia e recuperação de componentes.

Conforme questionário aplicado a um dos responsáveis pela filial pesquisada, no que diz respeito ao descarte de filtros de óleo lubrificante, a empresa tem como padrão o armazenamento dos filtros usados em tambores identificados e cobertos. Que é justamente o que o Guia Básico de Gerenciamento de óleos lubrificantes usados ou contaminados (2008) orienta, que os resíduos devem ser acondicionados de forma segura para que não contaminem o meio ambiente e não sejam contaminados por outras substâncias.

Com relação ao destino dos filtros contaminados o respondente afirmou que os filtros ficam em estoque até que seja saturada a capacidade de armazenamento e que, posteriormente, são recolhidos por uma empresa credenciada que emite laudo de coleta.

Sobre as orientações repassadas aos funcionários sobre a importância do descarte correto dos filtros lubrificantes e se as informações são focadas nos prejuízos ambientais ou financeiros para a empresa, o representante da organização informou que as instruções são focadas tanto no prejuízo ambiental que o descarte inadequado pode ocasionar quanto na esfera financeira, uma vez que o descarte inadequado ocasiona crime ambiental e as devidas sanções penais e pecuniárias. E, finalmente, sobre a fiscalização, o respondente informou que a empresa recebe constantemente a fiscalização do órgão municipal, por meio da Vigilância sanitária, e para estar em regularidade com o abastecimento de combustíveis é fiscalizada também pela CETESB (Companhia Ambiental do Estado de São Paulo).

Apesar da importância inegável do serviço de transportes sabe-se que o mesmo contribui em grande escala para a ocorrência de vários tipos de impactos ambientais. A empresa entrevistada, no entanto, participa do processo de logística reversa e ao realizar a troca do filtro, o armazenamento e descarte adequado deste resíduo, ainda que o faça para atender a fiscalização e a Lei, já estão trabalhando para reduzir consideravelmente as agressões ao meio ambiente.

\section{CONSIDERAÇÕES FINAIS}

O maior desafio à logística reversa, atualmente, é o alto custo operacional, considerando-se que o valor agregado do resíduo é baixo. No caso dos filtros do óleo lubrificante a situação é mais complicada ainda, já que o recolhimento e o processamento precisam ser feitos por empresas especializadas, o que torna o custo do processo elevado. Por outro lado, o retorno de resíduos às empresas de origem evita que esses produtos sejam descartados de forma inadequada e contaminem o meio ambiente. A empresa que adota a logística reversa tem grande chance de criar, através desse procedimento, uma imagem positiva com o consumidor 
final, que está cada dia preocupado com a degradação ambiental, aumentando sua competitividade no mercado. Além disso, o cumprimento da legislação evita multas e sanções ambientais.

A partir deste estudo pode-se inferir que a destinação correta dos filtros de óleo lubrificante pelas empresas de transporte é primordial tanto para a preservação do meio ambiente quanto para o aumento da consciência ambiental e o desenvolvimento sustentável do planeta, que trás beneficio para a sociedade em geral. E para que realmente sejam eficientes as ações de logística reversa são necessárias leis ambientais rígidas e fiscalização constante, que forçam as empresas a prestarem mais atenção ao processo e aos benefícios a curto e longo prazo que podem ser alcançados com essas ações. O presente trabalho traz limitações quanto o seu poder de generalização, uma vez que os resultados só podem ser atribuídos a empresa em análise. Para pesquisa futuras sugere-se empregar uma survey a uma amostra significativa que possa relacionar as práticas adotadas pelas empresas de transporte ao atendimento das normas ambientais vigentes.

\section{REFERÊNCIAS}

ALBERTINI, Gilberto. Regulamentação de Coleta e Descarte de Filtro de Óleo Lubrificante. Associação Brasileira das Empresas de Filtros e seus Sistemas Automotivos e Industriais. Abrafiltros. Guarulhos, 2010. Disponível em:< http://www.abrafiltros.org.br/apresentacoes/MANN-Apresentacao.pdf>. Acesso em: 04 jan de 2018.

ASSOCIAÇÃO BRASILEIRA DAS EMPRESAS DE FILTROS E SEUS SISTEMAS AUTOMOTIVOS E INDUSTRIAIS ABRAFILTROS. Programa Descarte Consciente Abrafiltros. 2012. Disponível em: http://www.abrafiltros.org.br/descarteConsciente/. Acesso em: 04 dez. 2017.

ASSOCIAÇÃO BRASILEIRA DE NORMAS TÉCNICAS - ABNT. NBR 10004: Resíduos Sólidos - Classificação: 2ed. 31 mai de 2004. Disponível em: http://www.v3.eco.br/docs/NBR-n-10004-2004.pdf. Acesso em 22 jan. 2018.

ASSOCIAÇÃO DE PROTEÇÃO AO MEIO AMBIENTE DE CIANORTE - ABRAMAC. Guia básico de gerenciamento de óleos lubrificantes usados ou contaminantes. 2007. Disponível em: http://www.sindilub.org.br/guia.pdf. Acesso em: 20 dez. 2017.

ATAÍDE, Leni de. O Sistema da Logística Reversa Pós-Consumo. Disponível em: http://aempreendedora.com.br/osistema-da-logistica-reversa-pos-consumo/. Acesso em 20 dez. 2017.

BALLOU, Ronald H. Gerenciamento da Cadeia de Suprimentos - Logística Empresarial - Título original: Business Logistics / Supply Chain Management. 5 ed., Tradução autorizada a partir do original em língua inglesa publicado por Pearson Education, sob o selo Prentice Hall 2004.

BRASIL, Presidência da República do Brasil. Casa Civil. Lei no 12.305, de 2 agosto de 2010. Institui a Política Nacional de Resíduos Sólidos, altera a Lei $n^{\circ}$ 9.605, de 12 de fevereiro de 1998; e dá outras providências. Brasília, DF. Disponível em: http://www.mma.gov.br/port/conama/legiabre.cfm?codlegi=636. Acesso em 14 dez. 2017.

CAVALCANTI, Clóvis. Desenvolvimento e natureza: estudos para uma sociedade sustentável. 4ed. Recife: Fundação Joaquim Nabuco/Cortez Editora, 2003. 


\section{Revista Nacional de}

Gerenciamento de Cidades

National Journal of Cities Management

FREITAS, Wesley Ricardo de Souza; LINK, Maria Rosa Quintino Link. Gestão Ambiental em Empresas de Transporte rodoviário de passageiros. XVII SEMEAD - Seminários em Administração, 2014.

GUARNIERI, Patrícia. Logística Reversa: em busca do equilíbrio econômico e ambiental. 1ed. Recife: Ed. Clube de Autores, 2011.

MAGALHÃES, Eduardo et al. Gestão da cadeia de suprimentos. Rio de Janeiro: Editora FGV, 2013.

NEVES, J. L. Pesquisa qualitativa - características, uso e possibilidades. Cadernos de pesquisa em administração, São Paulo. V. 1, no 3, 2ํosem. 1996.

SHIBAO. Fábio Ytoshi; MOORI, Roberto Giro; SANTOS, Mário Roberto dos. A logística reversa e a sustentabilidade ambiental. In: SEMINÁRIO EM ADMINISTRAÇÃO, 2010, São Paulo. Disponível em: http://web-

resol.org/textos/a_logistica_reversa_e_a_sustentabilidade_empresarial.pdf. Acesso em: 03 jan. 2018.

SOUZA, Cristiane Duarte de; SÁ, Natália Pecorone de. Logística reversa de pós-consumo: Aplicação do processo em uma empresa do ramo de construção civil. 2007. Disponível em:

http://inf.aedb.br/seget/artigos07/47_47_LOGISTICA\%20REVERSA\%20Seget.pdf. Acesso em 04 jan. 2018.

WILLE, Mariana Muller. Logística Reversa: Conceitos, Legislação e Sistema de custeio Aplicável. Disponível em: http://www.opet.com.br/faculdade/revista-cc-adm/pdf/n8/LOGISTICA-REVERSA.pdf. Acesso em: 20 dez. 2017. 